\title{
Percutaneous Coronary Interventional Treatment for Coronary Artery Disease and the Role of Antiplaplatelets Therapy: A Review of the Literature
}

\author{
Mostafa Al Shamiri, Abdulelah F. Al Mobeirek, Hanan Albackr, Turki B. Albacker* \\ King Fahad Cardiac Center, College of Medicine, King Saud University, Riyadh, KSA \\ Email: ${ }^{*}$ talbacker@ksu.edu.sa
}

Received 12 February 2014; revised 2 March 2014; accepted 20 March 2014

Copyright $@ 2014$ by authors and Scientific Research Publishing Inc.

This work is licensed under the Creative Commons Attribution International License (CC BY).

http://creativecommons.org/licenses/by/4.0/

(c) (i) Open Access

\begin{abstract}
Uses of balloon catheters or BMS for the treatment of coronary artery lesions shows good shortterm results but long-term follow up revealed restenosis in up to $20 \%-30 \%$ of patients. Thus new improvements to balloons and stents are always necessary to achieve the best results from percutaneous coronary intervention (PCI). Drug-eluting stents (DES) improved the principles of bare metal stents (BMS) by local drug release to inhibit neointimal growth. DES reduced the incidence of in-stent restenosis. These benefits and lower costs compared to surgical treatment make the DES an attractive alternative for the treatment of coronary artery disease. Different components of DES which include the polymers, drugs and the stents underwent progressive evolution, and these led to development of new generations of DES with variable types of drugs and polymers to fully absorbable stents. The concern of stent thrombosis still an issue and dual antiplatlets therapy (DAPT) is mandatory for variable time ranging from one month to one year. This article discusses the main available clinical trials in the developments of BMS, DES and the comparison between both with a prospective look at future technologies in the field, in addition to reviewing the current guideline in the uses of DAPT after PCI.
\end{abstract}

\section{Keywords}

Percutaneous Coronary Intervention; Coronary Artery Disease; Antiplatelets; Coronary Stents; Drug Eluting Stents; Bare Metal Stents

\footnotetext{
"Corresponding author.
} 


\section{Introduction}

Coronary artery disease (CAD) is the leading cause of death worldwide and will continue to be at least through the year 2030 [1]. The management of CAD would include life-style modification, drugs treatment and intervention in the form of percutaneous coronary intervention (PCI) or coronary artery bypass grafting (CABG). Large proportions of European coronary patients are failing to achieve lifestyle modification, risk factors control and therapeutic targets for the prevention of further disease, according to the results of the third EUROASPIRE survey [2]. In this survey, $17 \%$ smoked cigarettes, $35 \%$ were obese, $53 \%$ were centrally obese, $56 \%$ had blood pressure levels above target (140/90 $\mathrm{mmHg}, 130 / 80 \mathrm{mmHg}$ for patients with diabetes), 51\% had serum cholesterol levels above target $(4.5 \mathrm{mmol} / \mathrm{l}), 25 \%$ had a history of diabetes, of whom only $10 \%$ were adequately controlled (fasting glucose levels under $6.1 \mathrm{mmol} / \mathrm{l}$ ). Modern medical treatment is appropriate as an initial strategy in patients with stable CAD and mild angina. However, roughly one third of patients develop progressive or refractory angina and require invasive treatment over time [3].

Coronary angioplasty, conceptually described by Dotter and Judkins in 1964, was first performed by Andreas Gruntzig in 1977 [4]. Historically initial results with percutaneous balloon angioplasty only, raised concern regarding periprocedural complications, such as plaque rupture and coronary dissection, which are often clinically translated into acute myocardial infarction (MI), especially days following the procedure. Emergency coronary artery bypass grafting (CABG) due to acute vessel closure as a result of dissection was not uncommon. In addition, at follow-up, the benefits derived from revascularization were further counterbalanced by the high incidence of target vessel revascularization (TVR), and restenosis, which could reach $40 \%$ [5]. Coronary stents were developed in the mid-1980s and since then have seen major refinements in design and composition [6]. The first stent implantation was in 1986 by Sigwart, and the purpose was to overcome the issues of angioplasty [7].

\section{Methods}

We performed MEDLINE and Google searches for published articles including randomized controlled clinical trials and registries published between 2000 and 2013 using the keywords: coronary artery disease (CAD), percutaneous coronary angioplasty (PTCA), bare metal stents (BMS), drug-eluting stents (DES), antiplatelet therapy and percutaneous coronary angioplasty and dual antiplatelet therapy (DAPT) and percuaneous coronary intervention (PCI). Reference lists of selected articles were reviewed for other relevant citations, with special concentration on the studies which changed the practice.

\subsection{Types of Coronary Stents}

\subsubsection{Bare Metal Stent (BMS)}

Bare metal stent (BMS) beneficial effects, compared to percutaneous transluminal coronary angioplasty (PTCA), were documented by several studies in the form of reduction of TVR and restenosis rate [8] [9]. However long term follow-up revealed that in-stent restenosis (ISR), still as high as $20 \%-30 \%$ due to neointimal proliferation response to vessel injuries and migration of vascular smooth muscle cells (VSMCs) within the stents [10]. The risk of developing ISR is linked to a variety of clinical and procedural factors particularly diabetes, long lesion, and small vessels.

\subsubsection{Drug-Eluting Stents (DES)}

In order to find definitive solution to ISR, development of systemic drugs which later on led to eluting the stents with drugs which had anti proliferative properties, named drug eluting stents (DES) with the concept of local drug release at the site of tissue injuries to resist or prevent smooth muscle proliferation. The component of this novel approach includes: 1-the platform, 2-polymers and, 3-drugs. Changes in the above components led to development of different types and generations of DES.

\subsubsection{First Generation DES}

The first generation of DES has identical stent structure to their bare metal stents counterparts, with polymer and eluting drug applied to the surface. The platform is stainless steel with a strut thickness of $130-140 \mu \mathrm{m}$. Examples of this generation of stents include Sirolimus eluting CYPHER stent and Paclitaxel-eluting TAXUS stent. Sirolimus-eluting CYPHER stent (SES) has stainless steel platform and polymer of polyethylenevinylacetate 
and polybutylmethocrylate. A meta-analysis of data from four double-blinded studies with 1784 patients significantly found that TLR was reduced from 23.6\% with BMS to 7.8\% with Sirolimus-eluting CYPHER stent (SES) at 4 year [11]. Paclitaxel-eluting TAXUS stent (PES) has stainless steel platform and polymer of polylactide-coE-caprolactone. A meta-analysis of five double-blind trials in 3513 patients significantly revealed that TLR decreased from $20.0 \%$ with BMS to $10.1 \%$ with paclitaxel-eluting TAXUS stent (PES) at 4 years [12].

The studies of the first generation DES, documented the efficacy and safety of both Sirolimus and Paclitaxel anti prolifearative drugs. However Sirolimus is the only drug which can elute the stent without the need of polymers. The REALITY [13], and The SORT-OUT II [14], trials revealed no difference in the performance of both type of first generation DES, although type of them is obsolete as the newer generation overcome their use. Table 1 summarizes the different outcome trials and registries comparing BMS and DES.

\subsubsection{Second Generation DES}

In addition to incorporating newer medications (Everolimus and Zotarolimus), second-generation DES has more biocompatible polymers and utilizes cobalt or platinum chromium, with stent struts measuring only $80-90 \mu \mathrm{m}$ [19].

Everolimus-eluting XIANCE V stents have Cobalt Chromium platform and polymer of poly-n-butyl Methacrylate (PBMA). The same product of Boston Scientific, PRUMUS stent [20]. The large-scale SPIRIT IV trial compared EES with PES, in 3690 patients the primary clinical endpoint target lesion failure was significantly reduced by $38 \%$ in favor of EES, $(P=0.001)$. In addition, the rate of MI was lower with EES than PES, $(P=$ $0.02)$, whereas there were no differences with respect to overall and cardiac death.

ENDEAVOR Zatrolimus eluting stent (ZES) has Cobalt Chromium platform and polymer of Phosphorylcholine. ZES has been compared with both first and second-generation DES. ENDEAVOR III compared ZES with SES in a non inferiority trial with a primary angiographic endpoint, ZES was found inferior to SES regarding late loss [21]. ENDEAVOR IV compared ZES with PES in a non inferiority, randomized trial enrolling 1548 patients with a primary clinical endpoint of target vessel failure, ZES met its primary clinical endpoint of non inferiority on target vessel failure at 9 months. In the angiographic arm of the trial, ZES did not achieve the pre-specified secondary endpoint of in-segment late loss, $P=0.023$ [22]. Comparing Endeavor resolute Zatrolimus with Everolimus XIANCE V revealed that Zatrolimus is non-inferior to Everolimus [23].

\subsubsection{Third-Generation DES}

Although the coatings of these stents contain the same established drug and durable polymer combinations as their second generation counterparts, the design and material of their bare-metal stent platforms have been changed substantially. A Cobalt-Chromium-based Zotarolimus-eluting stent, made from a single sinusoidalformed wire (Resolute Integrity, Medtronic, Santa Rosa, CA, USA), and a laser cut Platinum-Chromium-based

\begin{tabular}{|c|c|c|c|c|c|c|}
\hline Study name/Year & Patient No. & DES & BMS & P-value & Outcome & Reference \\
\hline SERIU 2003 & 1058 & $\begin{array}{c}\text { SES } \\
7.1\end{array}$ & 18.9 & $<0.001$ & MACE & [15] \\
\hline \multirow{2}{*}{$\begin{array}{c}\text { Pooled analysis of data } \\
\text { comparing SES vs BMS } \\
2007\end{array}$} & \multirow[t]{2}{*}{878} & $\begin{array}{l}\text { SES } \\
93.3\end{array}$ & 94.6 & 0.28 & 4 year survival & \multirow[t]{2}{*}[16]{} \\
\hline & & 3.4 & 3.2 & 0.89 & ST & \\
\hline Roterdam registry 2008 & 958 & $\begin{array}{c}\text { SES } \\
23\end{array}$ & 28.7 & 0.05 & MACE & [17] \\
\hline $\begin{array}{c}\text { A pooled safety analysis } \\
\text { of date comparing PS vs } \\
\text { BMS } 2007\end{array}$ & 2797 & $\begin{array}{c}\text { PS } \\
92.9\end{array}$ & 92 & 0.78 & 4 year survival & [18] \\
\hline Taxus II/2009 & 536 & $\begin{array}{c}\text { PS } \\
20.4\end{array}$ & 27.6 & 0.01 & MACE & [12] \\
\hline
\end{tabular}

MACE: major adverse cardiac events. ST: stent thrombosis. 
Everolimus-eluting stent (Promus Element, Boston Scientific, Natick, MA, USA), are two such third-generation drug-eluting stents. Although some authorities [24], consider this as second generation with modification of platform, DUTCH PEERS trial consider these changes as third generation [25], which concludes that Both stents were similarly efficacious and safe, and provided excellent clinical outcomes, especially in view of the large number of patients who presented with acute myocardial infarctions.

\subsubsection{New Generations of DES}

The concept for the development of DES that have degradable polymers or are completely free of polymers and absorbable, is the dream of the intervention communities, as this innovative technology will reduce the chances of stent thrombosis and the requirement of long duration of dual anti-platelets therapy (DAPT). Durable polymers used in DES may play a central role in impaired healing by triggering a chronic inflammatory reaction, which is why there are continuous efforts aiming to eliminate permanent polymers. The biodegradable polymer was used in the LEADERS trial. Patients were allocated on a 1:1 basis to treatment with a stent eluting biolimus-A9 with a biodegradable polylactic acid polymer (BioMatrix Flex, Biosensors Inc., Newport Beach, CA, USA) or a Sirolimus-eluting stent with a durable polymer (Cypher SELECT, Cordis, Miami Lakes, FL, USA). The results suggest that a Biolimus eluting stent from a biodegradable polymer represents a safe and effective alternative to Sirolimus eluting stent from a durable polymer in patients with chronic stable coronary artery disease or acute coronary syndromes [26].

The polymer-free Biolimus-eluting stent (BES-PF, $\mathrm{N}=50$ ) has been directly compared with the Paclitaxel-eluting TAXUS LIBERTE' stent $(\mathrm{N}=25)$ in a randomized clinical study with the primary endpoint of late loss at 4 months which confirm significant reduction of late loss with polymer free stents [27]. In ISAR-TEST-3 trial, Polymer-Free Sirolimus-Eluting CYPHER stents also revealed reduced late loss [28]. With the encouraging results of biodegradable polymers and polymers free stents, the manufacturers of drug eluting stent started thinking of complete biodegradable and bio-absorbable stents.

\subsubsection{Fully Bio-Absorbable DES}

BMS were introduced to overcome the limitations of balloon angioplasty by scaffolding the vessel wall and prevention of acute recoil. However, stent mediated arterial injury resulted in neointimal hyperplasia, which was more pronounced following BMS implantation than balloon angioplasty alone. This limitation leads to the introduction of DES with release of anti-proliferative agents and potent suppression of neointimal hyperplasia. Since both shortcomings, acute recoil and neointimal hyperplasia, are relatively short lived phenomena, coronary artery stents of metal origin do not exert any long-term benefit, but may rather be the source of late adverse events including late stent thrombosis, prevent late lumen vessel enlargement, hinder surgical revascularization, and impair imaging quality with multi-slice CT.

Fully bio-absorbable DES has been developed to overcome these drawbacks. Four fully bioabsorbable stent platforms are under investigation:

1) Bioabsorbable magnesium alloy stent (Biotronik AG, Zurich, Switzerland).

The PROGRESS-AMS, included a 71 patients with de novo single vessel in a non-randomized trial with angiographic and IVUS assessment at 4 months and clinical follow-up at 1 year [29]. it conclude that biodegradable magnesium stents can achieve an immediate angiographic result similar to the result of other metal stents and can be safely degraded after 4 months where small remnant of struts seen with IVUS.

2) Bio-absorbable Everolimus-eluting XIENCE V stent (BVS, Abbott Vascular, Santa Clara, CA, USA).

The bio-absorbable Everolimus-eluting stent BVS has been evaluated in an observational first-in-man study of 30 patients with single de novo coronary artery lesions (ABSORB) [30]. At 2 years of follow-up, the device has been shown to be safe with no cardiac deaths, target lesion revascularizations, or stent thromboses and only one non-Q wave MI. Four-year clinical results of ABSORB demonstrated a sustained low MACE rate (3.4\%) without any late complications such as stent thrombosis [31]. ABSORB-EXTEND showed that treatment of longer lesions and smaller vessels without obligatory IVUS use is safe and efficacious at one month [32]. However, bioresorbable vascular scaffold was associated with a higher incidence of post-procedural side branch occlusion SBO was higher compared with EES [33]. In 2012 BVS ABSORB ${ }^{\mathrm{TM}}$ was approved as the first biodegradable scaffold for the treatment of coronary artery disease in EU and other countries, with a limitation of use only for experienced and trained interventional cardiologists [34], although there is a restriction of use to on la- 
bel but like all previous generation of stents off labeled use become a usual practice a fully absorbable stent is promising and it may be the future solution. However long-term follow up of randomized control trials is needed.

3) Tyrosine polycarbonate bio-absorbable stent (Reva Medical Inc., San Diego, CA). The Igaki-Tamai stent is made of a PLLA (poly-l-lactic acid) monopolymer, has thickness of $0.17 \mathrm{~mm}$, and has a zigzag helical coil pattern, it was used without drug administration and it proved that it is safe and effective [35].

4) BTI Salicylate-based Polyanhydride ester bio-absorbable Sirolimus-eluting CYPHER stent (Bioabsorbable Therapeutics Inc., CA, USA).

\section{Role of Oral Anti-Platelets Therapy Post PCI}

Dual anti platelets therapy (DAPT) is important as adjunctive treatment for patients who undergo percutaneous coronary intervention (PCI), with or without acute coronary syndrome. Historically when plane old balloon angioplasty (BOPA) were used to open coronary artery, there were some limitation in the success of the procedure, this include dissection, recoil closure of the vessels and thrombosis, subsequently the bare metal stent developed to overcome these complication, however it used to cause significant acute stent thrombosis (ST) which used to be treated with different anticoagulation and aspirin but still ST used to result in $50 \%$ of myocardial infarction and $20 \%$ of death [36]. The development of new antiplatelet agents led to a breakthrough in the use of coronary stents with the adoption of a dual anti-platelet treatment (DAPT), combining aspirin with a Thienopyridine [37].

Aspirin and Ticlopidine were used initially; however, Ticlopidine was soon replaced with Clopidogrel, which is more effective and better tolerated. PCI-CURE trial showed that in patients with acute coronary syndrome (ACS) receiving aspirin, a strategy of Clopidogrel pre-treatment followed by long-term therapy is beneficial in reducing major adverse cardiac events (MACE), compared with placebo [38], since then DAPT became a corner stone for treatment post PCI patients.

The most worrisome consequences for early discontinuation of antiplatelet therapy are the stent thrombosis (ST). In the majority of cases, stent thrombosis is a catastrophic event, resulting in life-threatening complications. In a pooled analysis of 6 trials and registries from the 1990s, the incidence of death or MI associated with angiographically documented stent thrombosis was found to be $64.4 \%$ [39]. Stent thrombosis most commonly occurs in the first month after stent implantation, and in this interval, it is referred to as "subacute" stent thrombosis. Historically, DAPT was given for one month for BMS and three to six months for DES. However, numerous cases of "late" stent thrombosis, particularly in patients who have been treated with DES, have been described as occurring months or even years after stent implantation based on BASKET-LATE study [40]. In view of regular use of DAPT and the development of stronger and new antiplatelets, we will review in the following text different evidences on the uses of DAPT and it is duration highlighting the most recent guidelines.

In the recent European Society of Cardiology (ESC) clinical practice guidelines, the following guidelines were included:

For the management of acute myocardial infarction in patients presenting with ST-segment elevation myocardial infarction (STEMI) [41], recommended periprocedural antithrombotic medication in primary percutaneous coronary intervention are:

1) Aspirin oral or i.v. (if unable to swallow) is recommended (IB).

2) An ADP-receptor blocker is recommended in addition to aspirin (1A). Options are:

a) Prasugrel in Clopidogrel-naive patients, if no history of prior stroke/TIA, age $<75$ years. (IB);

b) Ticagrelor (IB);

c) Clopidogrel, preferably when Prasugrel or Ticagrelor are either not available or contraindicated (IC).

For routine therapies in the acute, sub acute and long term phase of ST-segment elevation myocardial infarction, the followings are recommended:

DAPT with aspirin and an oral ADP receptor antagonist must be continued for up to 12 months after STEMI (IC), with a strict minimum of:

a) 1 month for patients receiving BMS (bare metal stent) (IC);

b) 6 months for patients receiving DES (drug eluting stent) (IIb-B);

c) DAPT should be used up to 1 year in patients with STEMI who did not receive a stent (IIa-C).

For ACS without ST segment elevation [42], the followings are recommended:

1) Prasugrel (60-mg loading dose, 10-mg daily dose) is recommended for P2Y12-inhibitor-naïve patients (es- 
pecially diabetics) in whom coronary anatomy is known and who are proceeding to PCI unless there is a high risk of life-threatening bleeding or other contraindications (IB).

2) Clopidogrel (300-mg loading dose, 75-mg daily dose) is recommended for patients who cannot receive Ticagrelor or Prasugrel (IA).

3) A 600-mg loading dose of Clopidogrel (or a supplementary 300-mg dose at PCI following an initial 300-mg loading dose) is recommended for patients scheduled for an invasive strategy when Ticagrelor or Prasugrel is not an option (IB).

Table 2: compare the rates of ischemic and bleeding events of oral (DAPT) drug trials TRITO-TIMI-38, [43] and PLTO [44] for Acute Coronary Syndrome Prasugrel and Ticagrelol versus Clopidogrel.

For stable CAD [45], the followings are recommended:

1) Aspirin is recommended for elective stenting (IB).

2) Clopidogrel is recommended for elective stenting (IA).

3) Prasugrel or ticagrelor should be considered in patients with stent thrombosis on clopidogrel without treatment interruption (IIa C).

4) Prasugrel may be considered in specific high risk situation of elective stenting (e.g. left main stenting, high risk of stent thrombosis; diabetes) (IIb C).

5) Pretreatment with Clopidogrel (when coronary anatomy is not known) is not recommended (IIIA).

6) Prasugrel or Ticagrelor is not recommended in low risk elective stenting (IIIC).

Duration of antiplatelet after stenting of stable angina patients:

1) Single antiplatelet therapy usually recommended indefinitely (IA).

2) DAPT is indicated after BMS for at least 1 month (IA).

3) DAPT is indicated for 6 to 12 months after 2nd generation DES (IB).

4) DAPT may be used for more than 1 year in patients at high ischemic risk (e.g. stent thrombosis, recurrent ACS on DAPT, post MI/diffuse CAD) and low bleeding risk (IIb B).

5) DAPT for 1 to 3 months may be used after DES implantation in patients at high bleeding risk or with undeferrable surgery or concomitant anticoagulant treatment (IIb C).

\section{Conclusion}

Coronary artery disease management progressively progressed with the evolution of different generations of drug eluting stents and different types of antiplatelet drugs leading to significant reduction in the number of patients going for coronary artery bypass grafting (CABG) with almost equal outcomes. Drug-eluting stents (DES) have improved the principles of bare metal stents (BMS) by neointimal growth inhibition through local drug release. DES significantly reduced the incidence of in-stent restenosis. These benefits and lower costs compared to surgical treatment make the DES a more attractive alternative for the treatment of coronary artery disease. However the concern of stent thrombosis still an issue and dual antiplatlets therapy (DAPT) is mandatory for variable time ranging from one month to one year. The new bioabsorbable stents may require shorter duration of DAPT and may not preclude the future need of CABG.

Table 2. Rate of ischemic and bleeding events in DAPT trials for acute coronary syndrome.

\begin{tabular}{ccccccc}
\hline \multirow{2}{*}{ Events } & \multicolumn{3}{c}{ TRITON-TIMI-38 [43] } & \multicolumn{3}{c}{ PLATO [44] } \\
\cline { 2 - 7 } & Prasugrel & Clopidogrel & P-value & Tricagrelor & Clopidogrel & P-value \\
\hline $\begin{array}{c}\text { Death MI or stroke\% } \\
\text { Death from }\end{array}$ & 9.9 & 12.1 & $<0.001$ & 10.2 & 12.3 & $<0.001$ \\
$\begin{array}{c}\text { cardiovascular cause } \\
\text { Major bleeding (TIMI) } \\
\text { non CABG }\end{array}$ & 2.1 & 2.4 & 0.31 & 4.0 & 5.1 & 0.001 \\
$\begin{array}{c}\text { Fatal bleeding } \\
\text { Intracranial bleeding }\end{array}$ & 0.4 & 1.8 & 0.03 & 7.9 & 0.7 & 0.57 \\
\hline
\end{tabular}




\section{References}

[1] Mathers, C.D. and Loncar, D. (2006) Projections of Global Mortality and Burden of Disease from 2002 to 2030. PLOS Medicine, 3, e442. http://dx.doi.org/10.1371/journal.pmed.0030442

[2] Kotseva, K., Wood, D., De Backer, G., et al. (2009) EUROASPIRE III: A Survey on the Lifestyle, Risk Factors and Use of Cardioprotective Drug Therapies in Coronary Patients from Twenty-Two European Countries. European Journal of Cardiovascular Prevention \& Rehabilitation, 16, 121-137. http://dx.doi.org/10.1097/HJR.0b013e3283294b1d

[3] Boden, W.E., O’Rourke, R.A., Teo, K.K., et al. (2007) Optimal Medical Therapy with or without PCI for Stable Coronary Disease. New England Journal of Medicine, 356, 1503-1516. http://dx.doi.org/10.1056/NEJMoa070829

[4] Gruntzig, A. (1978) Trans Luminal Dilatation of Coronary-Artery Stenosis. Lancet, 1, 263. http://dx.doi.org/10.1016/S0140-6736(78)90500-7

[5] Miller, J.M., Ohmann, E.M. and Moliterno, D.J. (1999) Restenosis: The Critical Issues. In: Topol, E.J., Ed., Textbook of Interventional Cardiology, 3rd Edition, Sunders, 379-415.

[6] Garg, S. and Serruys, P.W. (2010) Coronary Stents: Current Status. Journal of the American College of Cardiology, 56, S1-S42. http://dx.doi.org/10.1016/j.jacc.2010.06.007

[7] Sigwart, U., Puel, J., Mirkovitch, V., et al. (1987) Intravascular Stents to Prevent Occlusion and Restenosis after Transluminal Angioplasty. New England Journal of Medicine, 316, 701-706. http://dx.doi.org/10.1056/NEJM198703193161201

[8] Fischman, D.L., Leon, M.B., Baim, D.S., Stent Restenosis Study Investigators, et al. (1994) A Randomized Comparison of Coronary-Stent Placement and Balloon Angioplasty in the Treatment of Coronary Artery Disease. New England Journal of Medicine, 331, 496-501. http://dx.doi.org/10.1056/NEJM199408253310802

[9] Serruys, P.W., de Jaegere, P., Kiemeneij, F., BENESTENT Study Group, et al. (1994) A Comparison of Balloon-Expandable-Stent Implantation with Balloon Angioplasty in Patients with Coronary Artery Disease. New England Journal of Medicine, 331, 489-495. http://dx.doi.org/10.1056/NEJM199408253310801

[10] Hoffmann, R., Mintz, G.S., Dussaillant, G.R., et al. (1996) Patterns and Mechanisms of In-Stent Restenosis. A Serial Intravascular Ultrasound Study. Circulation, 94, 1247-1254. http://dx.doi.org/10.1161/01.CIR.94.6.1247

[11] Caixeta, A., Leon, M.B., Lansky, A.J., et al. (2009) 5-Year Clinical Outcomes after Sirolimus-Eluting Stent Implantation Insights from a Patient-Level Pooled Analysis of 4 Randomized Trials Comparing Sirolimus-Eluting Stents with Bare-Metal Stents. Journal of the American College of Cardiology, 54, 894-902. http://dx.doi.org/10.1016/j.jacc.2009.04.077

[12] Silber, S., Colombo, A., Banning, A.P., et al. (2009) Final 5-Year Results of the TAXUS II Trial. A Randomized Study to Assess the Effectiveness of Slow- and Moderate-Release Polymer-Based Paclitaxel-Eluting Stents for de novo Coronary Artery Lesions. Circulation, 13, 1498-1504. http://dx.doi.org/10.1161/CIRCULATIONAHA.109.849877

[13] Morice, M.C., Colombo, A., Meier, B., et al. (2006) Sirolimus- vs Paclitaxel-Eluting Stents in de novo Coronary Artery Lesions: The REALITY Trial: A Randomized Controlled Trial. JAMA, 295, 895-904. http://dx.doi.org/10.1001/jama.295.8.895

[14] Galloe, A.M., Thuesen, L., Kelbaek, H., et al. (2008) Comparison of Paclitaxel- and Sirolimus-Eluting Stents in Everyday Clinical Practice: The SORT OUT II Randomized Trial. JAMA, 299, 409-416. http://dx.doi.org/10.1001/jama.299.4.409

[15] Moses, J.W., Leon, M.B., Popma, J.J. and SIRIUS Investigators (2003) Sirolimus-Eluting Stents versus Standard Stents in Patients with Stenosis in a Native Coronary Artery. New England Journal of Medicine, 349, 1315-1323. http://dx.doi.org/10.1056/NEJMoa035071

[16] Spaulding, C., Daemen, J., Boersma, E., Cutlip, D.E. and Serruys, P.W. (2007) A Pooled Analysis of Data Comparing Sirolimus-Eluting Stents with Bare-Metal Stents. New England Journal of Medicine, 356, 989-997. http://dx.doi.org/10.1056/NEJMoa066633

[17] Daemen, J., Kukreja, N., van Twisk, P.-H., et al. (2008) Four-Year Clinical Follow-Up of the Rapamycin-Eluting Stent Evaluated at Rotterdam Cardiology Hospital Registry. American Journal of Cardiology, 101, 1105-1111. http://dx.doi.org/10.1016/j.amjcard.2007.11.074

[18] Daemen, J., Spaulding, C., Jacob, S., et al. (2007) A Pooled Safety Analysis of Data Comparing Paclitaxel-Eluting Stents with Bare-Metal Stents. EuroIntervention, 3, 392-399. http://dx.doi.org/10.4244/EIJV3I3A70

[19] Chitkara, K. and Pujara, K. (2010) Drug-Eluting Stents in Acute Coronary Syndrome: Is There a Risk of Stent Thrombosis with Second-Generation Stents? The European Journal of Cardiovascular Medicine, 1, 20-24. http://dx.doi.org/10.5083/ejcm.20424884.10

[20] Stone, G.W., Rizvi, A. and Newman, W. (2010) Everolimus-Eluting versus Paclitaxel-Eluting Stents in Coronary Artery Disease. New England Journal of Medicine, 362, 1663-1674. http://dx.doi.org/10.1056/NEJMoa0910496 
[21] Kandzari, D.E., Leon, M.B., Popma, J.J., Fitzgerald, P.J., O’Shaughnessy, C., Ball, M.W., Turco, M., Applegate, R.J., Gurbel, P.A., Midei, M.G., Badre, S.S., Mauri, L., Thompson, K.P., LeNarz, L.A. and Kuntz, R.E. (2006) Comparison of Zotarolimus-Eluting and Sirolimus-Eluting Stents in Patients with Native Coronary Artery Disease: A Randomized Controlled Trial. Journal of the American College of Cardiology, 48, 2440-2447. http://dx.doi.org/10.1016/j.jacc.2006.08.035

[22] Leon, M.B. (2007) ENDEAVOR 4: A Randomized Comparison of a Zotarolimus-Elutingstent and a Paclitaxel-Eluting Stent in Patients with Coronary Artery Disease: 8-Month Angiographic and 9- and 12-Month Clinical Results. Trancatheter Cardiovascular Therapeutics, 22 October 2007, Washington DC.

[23] Serruys, P.W., Silber, S., Garg, S., et al. (2010) Comparison of Zotarolimus-Eluting and Everolimus-Eluting Coronary Stents. New England Journal of Medicine, 363, 136-146. http://dx.doi.org/10.1056/NEJMoa1004130

[24] Raber, L. and Windecker, S. (2011) Current Status of Drug-Eluting Stents. Cardiovascular Therapeutics, 29, 176-189. http://dx.doi.org/10.1111/j.1755-5922.2010.00144.x

[25] von Birgelen, C., Sen, H., Lam, M.K., Danse, P.W., Jessurun, G.A.J., Hautvast, R.W.M., van Houwelingen, G.K., Schramm, A.R., Joe Gin, R.M.T., Louwerenburg, J.W., de Man, F.H.A.F., Stoel, M.G., Löwik, M.M., Linssen, G.C.M., Saïd, S.A.M., Nienhuis, M.B. and Verho, P.M.J. (2013) Third-Generation Zotarolimus-Eluting and Everolimus-Eluting Stents in All-Comer Patients Requiring a Percutaneous Coronary Intervention (DUTCH PEERS): A Randomised, SingleBlind, Multicentre, Non-Inferiority Trial. Lancet, 383, 413-423. http://dx.doi.org/10.1016/S0140-6736(13)62037-1

[26] Windecker, S., Serruys, P.W., Wandel, S., et al. (2008) Biolimuseluting Stent with Biodegradable Polymer versus Sirolimus-Eluting Stent with Durable Polymer for Coronary Revascularisation (LEADERS): A Randomized Noninferiority Trial. Lancet, 372, 1163-1173. http://dx.doi.org/10.1016/S0140-6736(08)61244-1

[27] Grube, E. (2009) A Prospective, Randomized, Non-Inferiority Trial Comparing Biolimus Drug Coated-Polymer Free Stent BioFreedom versus Paclitaxel-Eluting Stent with Durable Polymer TAXUS Liberte. Trancatheter Cardiovascular Therapeutics, 24 September 2009, San Francisco.

[28] Mehilli, J., Byrne, R.A., Wieczorek, A., Iijima, R., Schulz, S., Bruskina, O., Pache, J., Wessely, R., Schömig, A. and Kastrati, A. (2008) Randomized Trial of Three Rapamycin-Eluting Stents with Different Coating Strategies for the Reduction of Coronary Restenosis. European Heart Journal, 29, 1975-1982. http://dx.doi.org/10.1093/eurheartj/ehn253

[29] Erbel, R., Di Mario, C., Bartunek, J., et al. (2007) Temporary Scaffolding of Coronary Arteries with Bioabsorbable Magnesium Stents: A Prospective, Nonrandomized Multicentre Trial. Lancet, 369, 1869-1875. http://dx.doi.org/10.1016/S0140-6736(07)60853-8

[30] Serruys, P.W., Ormiston, J.A., Onuma, Y., Regar, E., Gonzalo, N., Garcia-Garcia, H.M., Nieman, K., Bruining, N., Dorange, C., Miquel-Hébert, K., Veldhof, S., Webster, M., Thuesen, L. and Dudek, D. (2009) A Bioabsorbable EverolimusEluting Coronary Stent System (ABSORB): 2-Year Outcomes and Results from Multiple Imaging Methods. Lancet, 373, 897-910. http://dx.doi.org/10.1016/S0140-6736(09)60325-1

[31] Dudek, D., Onuma, Y., Ormiston, J.A., Thuesen, L., Miquel-Hebert, K. and Serruys, P.W. (2012) Four-Year Clinical Follow-Up of the Everolimus-Eluting Bioresorbable Vascular Scaffold in Patients with de novo Coronary Artery Disease: The ABSORB Trial. EuroIntervention, 7, 1060-1061. http://dx.doi.org/10.4244/EIJV7I9A168

[32] Simsek, C., Magro, M., Onuma, Y., Boersma, E., Smits, P., Dorange, C., Veldhof, S., Regar, E., Serruys, P.W. and van Geuns, R.J. (2013) Procedural and Clinical Outcomes of the Absorb Everolimus-Eluting Bioresorbable Vascular Scaffold: One-Month Results of the Bioresorbable Vascular Scaffold Evaluated at Rotterdam Cardiology Hospitals (B-SEARCH). EuroIntervention, pii: 20121019-03.

[33] Muramatsu, T., Onuma, Y., García-García, H.M., Farooq, V., Bourantas, C.V., Morel, M.A., Li, X., Veldhof, S., Bartorelli, A., Whitbourn, R., Abizaid, A. and Serruys, P.W. (2013) Incidence and Short-Term Clinical Outcomes of Small Side Branch Occlusion after Implantation of an Everolimus-Eluting Bioresorbable Vascular Scaffold: An Interim Report of 435 Patients in the ABSORB-EXTEND Single-Arm Trial in Comparison With an Everolimus-Eluting Metallic Stent in the SPIRIT First and II Trials. Journal of the American College of Cardiology Cardiovascular Interventions, $\mathbf{6}$, 247-257.

[34] Rzeszutko, L., Depukat, R. and Dudek, D. (2013) Biodegradable Vascular Scaffold ABSORB BVS ${ }^{\mathrm{TM}}$-Scientific Evidence and Methods of Implantation. Postępy w Kardiologii Interwencyjnej, 9, 22-30.

[35] Tamai, H., Igaki, K., Kyo, E., Kosuga, K., Kawashima, A., Matsui, S., Komori, H., Tsuji, T., Motohara, S. and Uehata, H. (2000) Initial and 6-Month Results of Biodegradable Poly-l-Lactic Acid Coronary Stents in Humans. Circulation, 102, 399-404. http://dx.doi.org/10.1161/01.CIR.102.4.399

[36] Nath, F.C., Muller, D.W., Ellis, S.G., Rosenschein, U., Chapekis, A., Quain, L., Zimmerman, C. and Topol, E.J. (1993) Thrombosis of a Flexible Coil Coronary Stent: Frequency, Predictors and Clinical Outcome. Journal of the American College of Cardiology, 21, 622-627. http://dx.doi.org/10.1016/0735-1097(93)90093-G

[37] Schomig, A., Neumann, F.J., Kastrati, A., et al. (1996) A Randomized Comparison of Antiplatelet and Anticoagulant 
Therapy after the Placement of Coronary-Artery Stents. New England Journal of Medicine, 334, 1084-1089. http://dx.doi.org/10.1056/NEJM199604253341702

[38] Mehta, S.R., Yusuf, S., Peters, R.J., Bertrand, M.E., Lewis, B.S., Natarajan, M.K., Malmberg, K., Rupprecht, H.J., Zhao, F., Chrolavicius, S., Copland, I. and Fox, K.A.A. (2001) Effects of Pretreatment with Clopidogrel and Aspirin Followed by Long-Term Therapy in Patients Undergoing Percutaneous Coronary Intervention: The PCI-CURE Study. Lancet, 358, 527-533. http://dx.doi.org/10.1016/S0140-6736(01)05701-4

[39] Cutlip, D.E., Baim, D.S., Ho, K.K., Popma, J.J., Lansky, A.J., Cohen, D.J., Carrozza Jr., J.P., Chauhan, M.S., Rodriguez, O. and Kuntz, R.E. (2001) Stent Thrombosis in the Modern Era: A Pooled Analysis of Multicenter Coronary Stent Clinical Trials. Circulation, 103, 1967-1971. http://dx.doi.org/10.1161/01.CIR.103.15.1967

[40] Pfisterer, M., Brunner-La Rocca, H.P., Buser, P.T., Rickenbacher, P., Hunziker, P., Mueller, C., Jeger, R., Bader, F., Osswald, S. and Kaiser, C. (2006) Late Clinical Events after Clopidogrel Discontinuation May Limit the Benefit of DrugEluting Stents: An Observational Study of Drug-Eluting versus Bare-Metal Stents. Journal of the American College of Cardiology, 48, 2584-2591. http://dx.doi.org/10.1016/j.jacc.2006.10.026

[41] Steg, P.G., James, S.K., Atar, D., et al. (2012) ESC Guidelines for the Management of Acute Myocardial Infarction in Patients Presenting with ST-Segment Elevation. European Heart Journal, 33, 2569-2619. http://dx.doi.org/10.1093/eurheartj/ehs215

[42] Hamm, C.W., Bassand, J.P., Agewall, S., Bax, J., Boersma, E., Bueno, H., Caso, P., Dudek, D., Gielen, S., Huber, K., Ohman, M., Petrie, M.C., Sonntag, F., Uva, M.S., Storey, R.F., Wijns, W. and Zahger, D. (2011) ESC Guidelines for the Management of Acute Coronary Syndromes in Patients Presenting without Persistent ST-Segment Elevation. European Heart Journal, 32, 2999-3054. http://dx.doi.org/10.1093/eurheartj/ehr236

[43] Montalescot, G., Wiviott, S.D., Braunwald, E., Murphy, S.A., Gibson, C.M., McCabe, C.H., Antman, E.M. for the TRITON-TIMI 38 Investigators (2009) Prasugrel Compared with Clopidogrel in Patients Undergoing Percutaneous Coronary Intervention for ST-Elevation Myocardial Infarction (TRITON-TIMI 38): Double-Blind, Randomised Controlled Trial. Lancet, 373, 723-731. http://dx.doi.org/10.1016/S0140-6736(09)60441-4

[44] Wallentin, L., Becker, R.C., Budaj, A., Cannon, C.P., Emanuelsson, H., Held, C., Horrow, J., Husted, S., James, S., Katus, H., Mahaffey, K.W., Scirica, B.M., Skene, A., Gabriel Steg, P., Storey, R.F., Harrington, R.A. for the PLATO Investigators (2009) Ticagrelor versus Clopidogrel in Patients with Acute Coronary Syndromes. New England Journal of Medicine, 361, 1045-1057.

[45] Montalescot, G., Sechtem, U., et al. (2013) ESC Guidelines on the Management of Stable Coronary Artery Disease. European Heart Journal, 34, 2949-3003.

\author{
Abbreviations \\ $\mathrm{CAD}=$ coronary artery disease \\ BOPA $=$ plane old balloon angioplasty \\ PTCA = percutaneous transluminal coronary angioplasty \\ $\mathrm{PCI}=$ percutaneous coronaty intervention \\ BMS = bare metal stent \\ DES = drug eluting stent \\ DAPT $=$ dual antiplatelet therapy \\ ACS = acute coronary syndrome \\ STEMI = ST segment elevated myocardial infarction \\ NON STEMI = non ST segment elevated myocardial infarction \\ $\mathrm{CABG}=$ coronary artery bypass grafting \\ $\mathrm{MI}=$ myocardial infarction \\ MACE $=$ major adverse cardiac events \\ TVR $=$ target vessel revascularization \\ $\mathrm{TLR}=$ target lesion revascularization \\ ISR $=$ instent restenosis \\ VSMCs $=$ vascular smooth muscle cells \\ SES = Sirolimus-eluting stent \\ PES = Paclitaxel-eluting stent \\ EES = Everolimus-eluting stents \\ ZES = Zithrolimus-eluting stent \\ $\mathrm{BES}=$ Biolimus-eluting stent
}

